Article

\title{
Carbon Microparticles from Organosolv Lignin as Filler for Conducting Poly(Lactic Acid)
}

\author{
Janea Köhnke ${ }^{1}$ * , Christian Fürst ${ }^{2}$, Christoph Unterweger ${ }^{2}$, Harald Rennhofer ${ }^{3}$, \\ Helga C. Lichtenegger ${ }^{3}$, Jozef Keckes ${ }^{4}$, Gerhard Emsenhuber ${ }^{1}$, Arunjunai raj Mahendran ${ }^{2}$, \\ Falk Liebner ${ }^{1}$ and Wolfgang Gindl-Altmutter ${ }^{1}$ \\ 1 BOKU-University of Natural Resources and Life Science Vienna, Konrad Lorenz Strasse 24, A-3430 Tulln, \\ Austria; gerhard.emsenhuber@boku.ac.at (G.E.); falk.liebner@boku.ac.at (F.L.); \\ wolfgang.gindl-altmutter@boku.ac.at (W.G.-A.) \\ 2 Kompetenzzentrum Holz GmbH, Altenbergerstrasse 89, A-4020 Linz, Austria; c.fuerst@kplus-wood.at (C.F.); \\ c.untergweger@kplus-wood.at (C.U.); a.mahendran@kplus-wood.at (A.R.M.) \\ 3 BOKU-University of Natural Resources and Life Science Vienna, Peter Jordan Strasse 82, A-1190 Vienna, \\ Austria; harald.rennhofer@boku.ac.at (H.R.); helga.lichtenegger@boku.ac.at (H.C.L.) \\ 4 Department Materials Physics, University of Leoben, Jahnstrasse 12, A-8700 Leoben, Austria; \\ jozef.keckes@unileoben.ac.at \\ * Correspondence: janea.koehnke@boku.ac.at; Tel.: +43-1-47654-89181
}

Academic Editors: Hyeonseok Yoon and Changsik Song

Received: 4 April 2016; Accepted: 20 May 2016; Published: 26 May 2016

\begin{abstract}
Carbon microparticles were produced from organosolv lignin at $200{ }^{\circ} \mathrm{C}$ under argon atmosphere following oxidative thermostabilisation at $250{ }^{\circ} \mathrm{C}$. Scanning electron microscopy, X-ray diffraction, small-angle $X$-ray scattering, and electro-conductivity measurements revealed that the obtained particles were electrically conductive and were composed of large graphitic domains. Poly(lactic acid) filled with various amounts of lignin-derived microparticles showed higher tensile stiffness increasing with particle load, whereas strength and extensibility decreased. Electric conductivity was measured at filler loads equal to and greater than $25 \% w / w$.
\end{abstract}

Keywords: lignin; carbon; carbonisation; electric conductivity; SAXS; filled polymers; tensile testing

\section{Introduction}

Lignin is the second most abundant natural polymer. It is an amorphous, thermoplastic, three-dimensional, cross-linked and aromatic component of the cell wall, that consists of substituted phenylpropane units, whose pattern largely depends on the plant species. Formed by random radical dehydropolymerisation of the three main aromatic precursor compounds coumaryl, coniferyl and sinapyl alcohol, lignin has a great diversity of bonds and functional groups [1]. 15-O-4 bonds can account for up to 70 percent of all linkages between lignols, but other bond types play a crucial role with regard to lignin properties as well, such as ether and $C-C$ bonds as found in $B-5$ and $5-5^{\prime}$ structural units. This applies for the functional groups of lignin as well which comprise in particular methoxyl, carbonyl, carboxyl and hydroxyl groups [2].

Lignin is an essential component of lignocellulosic plant tissues where it acts as a connecting, stiffening matrix between cells, increases compression resistance, imparts hydrophobicity to the cell wall, and provides protection against microorganisms [3]. Lignocellulosic materials such as wood contain between about 15 and 40 percent lignin, which can be extracted to a large extent during wood pulping. Taking into consideration global pulp production, about 70 million tons of lignin are produced as a side product every year, dominated by kraft lignin, soda lignin and the various types of lignosulfonates [4]. Whilst the majority of lignin is still used as fuel despite its comparatively low heating value, only 1.7 percent of this valuable natural resource finds application in materials. 
Recent studies have confirmed renewed interest in using lignin as feedstock for the production of materials such as dispersants, binders or bulking agents [4]. A particular focus is currently on lignin-derived carbon fibres [5-8], which are hoped to become a low-cost alternative to high-quality carbon fibres derived from polyacrylonitrile. The application envisioned for lignin-derived carbon fibres is in lighter and hence fuel saving transportation devices.

Besides carbon fibre, carbon black has become a material that is of great technological and industrial importance because of its unique mechanical, chemical and electrical properties [9-11]. On the one hand, carbon black may reduce the overall material costs as low-cost filler in polymers, and on the other hand carbon black as filler can significantly improve the overall properties of plastics and elastomers, especially electric conductivity [12,13]. Carbon black is obtained through incomplete combustion or thermal degradation of fossil resources in absence of oxygen. According to the International Carbon Black Association (http:/ / www.carbon-black.org), more than 8 million metric tons of carbon black were produced worldwide in 2014, almost exclusively from fossil resources. Therefore, a viable bio-based alternative to fossil-derived carbon black is of great interest. It is proposed that lignin-derived carbon microparticles may represent such an alternative. In the present study we focus on organosolv lignin as a potential raw material for carbonisation. The organosolv pulping process, which is based on the lignin solubilisation ability of (acidic) aqueous alcohols at elevated temperature and pressure, is considered to have great potential for lignocellulose biorefinery as demonstrated by the pilot scale plant Leuna [14], even though commercial implementation has not happened yet. Numerous studies [15-18] have confirmed that organosolv lignins have superior quality because of their high purity, low molecular weight and narrow size distribution as well as their low sulfur and salt contents. In view of these advantageous properties, the feasibility of producing carbon microparticles from organosolv lignin will be evaluated together with selected properties of this novel material.

\section{Materials and Methods}

\subsection{Materials}

Organosolv lignin (Product number CP8068-03-9-BULK) was purchased from Chemical Point UG (Deisenhofen, Germany) (Element contents: C: 61.7\%, H: 5.3\%, N: 0.9\%, S: 0\%, O: 28.3\%, rest: 3.81\%. Chloroform (Purity: $\geqslant 99.5 \%$ was obtained from Sigma-Aldrich (Vienna, Austria) and poly(lactic acid) grade 2003D was purchased from Natureworks LLC (Minnetonka Boulevard, Minnetonka, MN, USA).

\subsection{Lignin Carbonisation}

Prior to carbonisation, lignin was thermostabilised to prevent particles from fusing during pyrolysis and graphitisation. For this purpose, organosolv lignin was evenly distributed in a crucible and heated at a rate of $0.01 \mathrm{~min}^{-1}$ to $250^{\circ} \mathrm{C}$ in ambient atmosphere using a drying oven. Carbonisation was conducted in a GERO HTK8 oven (volume $6 \mathrm{~L}$ ) using an argon gas flow of $150 \mathrm{~L} \cdot \mathrm{h}^{-1}$. The oven was set to a heating rate of $1^{\circ} \mathrm{C} \cdot \mathrm{min}^{-1}$ up to $500{ }^{\circ} \mathrm{C}(1 \mathrm{~h}$ holding step $), 5^{\circ} \mathrm{C} \cdot \mathrm{min}^{-1}$ up to $900{ }^{\circ} \mathrm{C}(1 \mathrm{~h}$ holding step) and finally $5{ }^{\circ} \mathrm{C} \cdot \mathrm{min}^{-1}$ up to $2000^{\circ} \mathrm{C}(1 \mathrm{~h}$ holding step).

\subsection{Characterisation of Lignin and Carbon Particles}

For scanning electron microscopy (SEM) and energy dispersive X-ray analysis (EDX) the samples were placed on a carbon conductive double coated tab and sputter-coated with a thin film of gold. Microscopy was conducted in a QuantaTM 250 field-emission environmental scanning electron microscope (FEI Europe B.V., Vienna, Austria) with a Shottky field emission gun operating at $10 \mathrm{kV}$ in high vacuum of $1 \times 10^{-6}$ mbar. Differential scanning calorimetry (DSC) data of both, untreated and thermostabilised, lignins were obtained with a DSC 200F3 Maia device (NETZSCH, Graz, Austria) and a heating rate of $10 \mathrm{~K} \cdot \mathrm{min}^{-1}$. Termogravimetric analyses were carried out using a TA Instruments TGA Q5000 (Waters GmbH, UB TA Instruments, Eschborn, Germany) with a heating rate of $20 \mathrm{~K} \cdot \mathrm{min}^{-1}$. 
Attenuated diffuse reflection Fourier transform infrared spectroscopy (ATR-FTIR) was performed on a Helios spectrometer (Ultrafast Systems BV, Amsterdam, The Netherlands) equipped with a Tensor 27 and a diamond crystal. Spectral resolution was $4 \mathrm{~cm}^{-1}$. The spectra were baseline corrected. Specific electrical resistivity was measured as described in Sánchez-González et al. [19]. X-ray diffraction (XRD) of the samples was performed using a 5-circle $\mathrm{X}$ ray diffractometer (SmartLab from Rigaku Co., Ettlingen, Germany) equipped with $\mathrm{Cu} \mathrm{K} \alpha$ radiation, a parabolic multilayer mirror in the primary beam and a secondary graphite monochromator. The samples were measured using a $2 \theta$ step of 0.02 degrees and $4 \mathrm{~s}$ dwell time.

Small angle X-ray scattering (SAXS) was used to obtain information about the nanostructure of the samples. Measurements were carried out with a three pinhole SMAX-3000 SAXS camera (Rigaku Co, Ettlingen, Germany) equipped with a copper target micro focus X-ray tube (MM002+ source with a wavelength of $\lambda=0.1541 \mathrm{~nm}$ ). Two dimensional scattering images were recorded with a TRITON 200 multi-wire $X$-ray detector. The scattering images were averaged azimuthally to gain information on the scattered intensity $\mathrm{I}(q)$ in dependence on the scattering vector $q$, which is related to the scattering angle $2 \theta$ and the wavelength $\lambda$ by the Bragg-equation:

$$
q=\frac{4 \pi}{\lambda} \times \sin \theta
$$

The obtained data were background corrected and analysed with respect to the pore structure.

At high q values the scattering intensity follows the Porod law:

$$
\mathrm{I}(q)=P q^{-n}
$$

The exponent $n$ is usually close to 4 for smooth surfaces and $P$ the Porod constant is proportional to the pore surface. The scattering invariant $Q$ is defined by

$$
Q=\int_{0}^{\infty} q^{2} I(q) d q
$$

and is a measure of the total scattering of the sample, related to the volumes of pores and matrix material. The ratio $P / Q$ is proportional to the specific inner surface $S^{*}=S / V$ of the sample with a proportionality factor given by the fractions of pores $\Phi_{1}$ and the matrix material $\Phi_{2}$, with $\Phi_{1}=1-\Phi_{2}$ :

$$
\frac{P}{Q}=\frac{1}{\pi \Phi_{1} \Phi_{2}} S^{*}
$$

The Guinier approximation was used at low $q$ to evaluate a pore radius of spherical pores $R$ from the radius of gyration $R_{\mathrm{g}}$, by $R^{2}=5 / 3 R_{\mathrm{g}}^{2}$ with:

$$
I(q) \sim I_{0} e^{-q^{2} R_{\mathrm{g}}^{2} / 3}
$$

\subsection{Preparation and Characterisation of Poly(Lactic Acid) Composites Containing Different Amounts of Lignin-Derived Carbon Microparticles}

Poly(lactic acid) (PLA) was dissolved in chloroform to give a concentration of $100 \mathrm{~g} \cdot \mathrm{L}^{-1}$. Defined amounts of lignin derived carbon microparticles ( $0-35 \mathrm{wt} \%$ related to the mass of composite) were then dispersed under stirring (ultra-turrax) in $100 \mathrm{~mL}$ aliquots of the PLA solution. After transferring the dispersions into petri dishes, the solvent was allowed to evaporate, slowed down by filter paper put on top of the petri dishes to obtain smooth polymer films. After about 16 hours the formed films were removed from the petri dishes, folded right in the middle obtaining a double-layer of film and hot pressed at $150{ }^{\circ} \mathrm{C}$. This procedure was repeated three-times in order to improve particle dispersion in the polymer. A final film thickness of $0.5 \mathrm{~mm}$ was obtained. Strips $(6 \mathrm{~mm} \times 60 \mathrm{~mm})$ were cut and tested for tensile strength on a Zwick Roell $20 \mathrm{kN}$ testing machine (Zwick GmbH \& Co. KG, 
Ulm, Germany) equipped with a $2.5 \mathrm{kN}$ load cell. Electrical resistivity of the composite films was determined according to EN ISO 3915 using the same type of strips.

\section{Results and Discussion}

\subsection{Scanning Electron Microscopy (SEM)}

Morphological investigation of the prepared lignin-derived carbon microparticles using SEM revealed a largely irregular shape and broad size distribution for all of the three types of particles studied, i.e., untreated lignin, thermostabilised lignin, and carbonised lignin (Figure 1). However, it can be seen that the particle size distribution is significantly affected by both thermostabilisation and carbonisation, as smaller particles are obtained with increasing mass loss by thermal degradation.
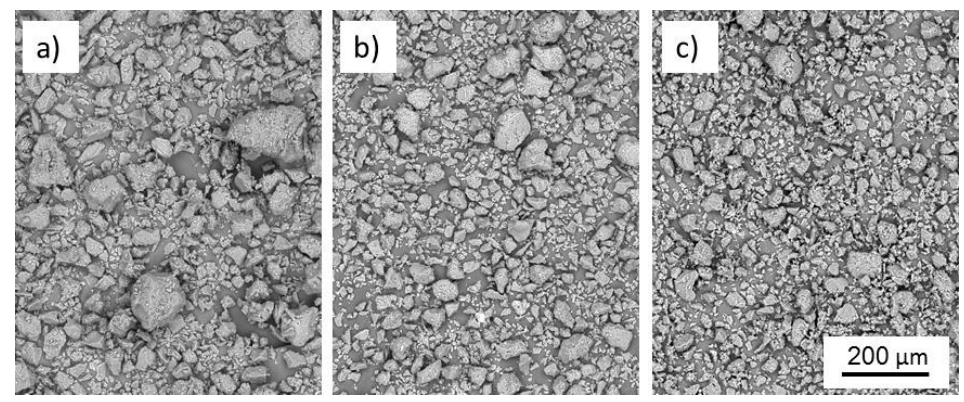

Figure 1. SEM micrographs of organosolv particles prior to (a) and after thermostabilisation (b) and carbonisation, respectively (c).

The average particle size of the native lignin was $9.1 \pm 10.3 \mu \mathrm{m}$, dropping to $7.0 \pm 7.5 \mu \mathrm{m}$ for the stabilised particles. The smallest average particle size was obtained for the carbonised particles $(5.3 \pm 6.4 \mu \mathrm{m})$. Box and whisker plots visualize skewed sized distributions for all types of particles in favor of smaller particles (Figure 2). A few large outliers with dimensions above $14 \mu \mathrm{m}$ are not shown in Figure 2, and their occurrence diminishes with every treatment step.

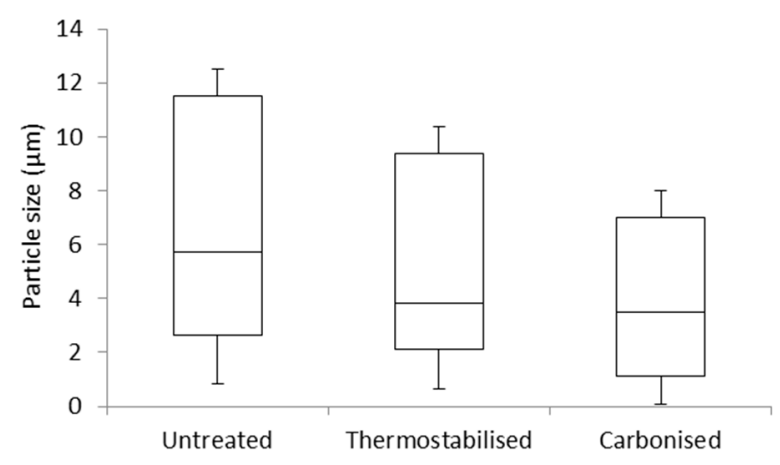

Figure 2. Particle size distribution of untreated, thermostabilised and carbonised organosolv lignin particles (outliers are not displayed; the box and whisker diagram is based on the minimum (lower whisker), the first quartile (bottom edge), the median (centre line), the third quartile (upper edge) and the maximum (upper whisker)).

Thermostabilisation (oxidative environment, $T \leqslant 250^{\circ} \mathrm{C}$ ) and carbonisation (inert gas, $T \leqslant 2000^{\circ} \mathrm{C}$ ) of organosolv lignin particles were accompanied by significant mass losses that accounted for $58 \%$ and $81 \%$, respectively, of the starting material. In view of the only moderate reduction in particle size observed, the substantial mass loss measured points towards increased porosity of the particles after 
treatment. Compared to the literature, the reduction in particle size and the mass loss observed in the present study is less pronounced than in the case of carbonised lignosulfonate, where an overall carbon yield of only $7.3 \%$ was obtained [20].

\subsection{Energy-Dispersive X-ray Spectroscopy (EDX)}

The EDX results shown in Figure 3 confirm extensive carbonisation of lignin after treatment at $2000{ }^{\circ} \mathrm{C}$, with more than $95 \%$ of sample mass converted to carbon. Besides oxygen and a trace of sodium, a small amount of silica was also detected. According to the silicon content of the parent material which was determined with 0.04 at $\%$ and the total mass yield of $19 \%$ there is a calculated total maximum of $0.2 \%$ silicon, which is in the same order of magnitude as EDX results. In good agreement with the fact that silica was detected in the carbonisation product, scanning electron microscopy revealed the presence of needle-shaped crystallites among the formed carbon particles (Figure 3). In these needles, reduced carbon content of 92.18 at \% and oxygen and silicon contents of 5.06 at \% and 2.37 at \%, respectively, were found.
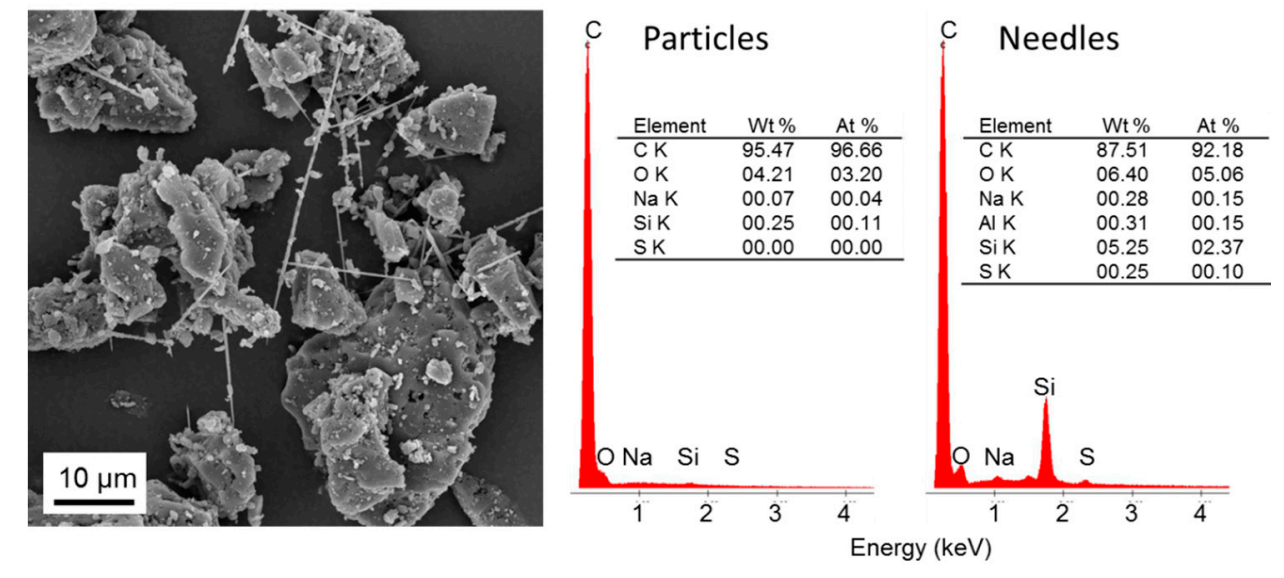

Figure 3. SEM image of carbonised lignin containing small amounts of needle-shape crystals (left) and results of EDX analyses (right) of both carbon particles and crystals.

It is well known that lignin of annual plants has a high content of silicates [21], so the organosolv lignin might be produced by annual plants such as grass or bamboo. Other studies showed that standard carbon black has a characteristic $\mathrm{O} / \mathrm{C}$ atomic ratio of $\leqslant 0.1$, which is much lower than the measured $\mathrm{O} / \mathrm{C}$ atomic ratio of our sample [22].

\subsection{Attenuated Diffuse Reflection Fourier Transform Infrared Spectroscopy (ATR-FTIR)}

The ATR-FTIR spectrum of unmodified organosolv lignin (Figure 4) as recorded in the vibration range of 4000-600 $\mathrm{cm}^{-1}$ (16 repetitions) was in good agreement with data published in Hage et al. [18]. Peak assignment based on the work of Norberg et al., Sharma et al., Braun et al. and Kubo et al. [23-26] confirmed the presence of hydroxyl groups due to phenolic or alcoholic components as shown in band (1) in the range of 3100 to $3500 \mathrm{~cm}^{-1}$. Band (2) at wavenumber of $2934 \mathrm{~cm}^{-1}$ displays aliphatic and aromatic carbons, and band (3) at wavenumber of $1690 \mathrm{~cm}^{-1}$ shows unconjugated groups of carbonyls. Bands (4) and (5) are "the fingerprint region" which means that they are typical for ATR-FTIR spectra of lignin and are associated with the aromatic ring modes at wavenumbers 1596 and $1510 \mathrm{~cm}^{-1}$, respectively. The band (6) at $1459 \mathrm{~cm}^{-1}$ represents $\mathrm{C}-\mathrm{H}$ stretching of the aromatic skeletal, same as band (7) $1421 \mathrm{~cm}^{-1}$. The bands (8), (9), and (11) at the wavenumbers 1328, 1212 and $1122 \mathrm{~cm}^{-1}$, respectively, display syringyl and guaiacyl units. The band (10) at $1168 \mathrm{~cm}^{-1}$ represents conjugated esters. Finally, band (12) at $1028 \mathrm{~cm}^{-1}$ is due to lignin-linked hemicelluloses and band (13) at wavenumber $832 \mathrm{~cm}^{-1}$ is caused by aromatic $\mathrm{C}-\mathrm{H}$ out of plane bending. 


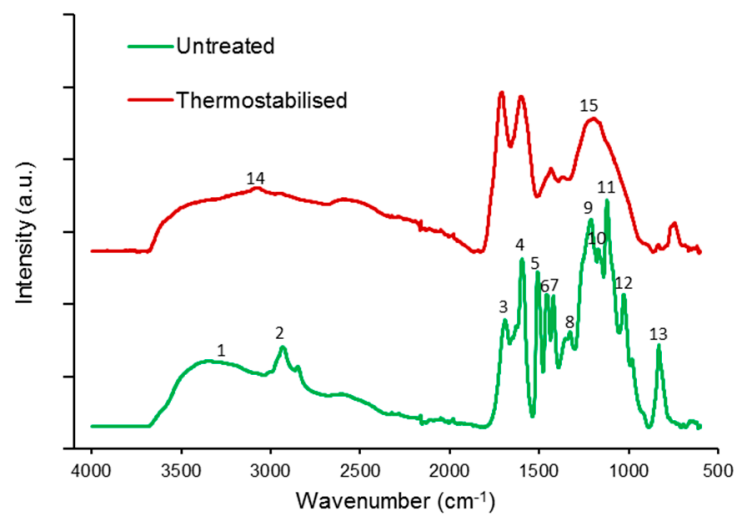

Figure 4. FTIR spectra of organosolv lignin particles before and after thermostabilisation.

After thermostabilisation, the FT-IR spectra lack peaks at bands (1) and (2) indicate a reduction of phenolic or alcoholic groups, and removal and methyl groups, respectively. In parallel, band (14) at wavenumber $3073 \mathrm{~cm}^{-1}$, associated with aromatic hydrocarbon, increases in intensity in the thermostabilised variant. In the fingerprint region, a very significant increase is seen in band (3) associated with the stretch of unconjugated carbonyls, probably an indicator for rearrangement and radical reactions with introducing oxidised structures to the lignin. Furthermore, the number of distinct bands in the spectral region between 1500 and $700 \mathrm{~cm}^{-1}$ is much reduced, with a broad peak remaining at position (15) at $1199 \mathrm{~cm}^{-1}$. This change in spectral features shows that carbonyl groups and methoxyl were removed during autoxidation reactions. Furthermore, crosslinking reactions in the $\mathrm{C} 5$ position of g-lignin units occur during the thermostabilisation. In summary, it can be said that there occurred dehydration and oxidation as well as carbonyl group formation and elimination during thermostabilisation in parallel to a decomposition of aliphatic units [27-30].

The thermal stabilisation process leads to lower content of oxygen, carbon and hydrogen caused by dehydration reactions, condensation, cross linking, autoxidation and elimination reactions. Byproducts of those reactions are water, carbon monoxide and carbon dioxide which are produced via formation of aromatic, keto, anhydride and ester linkages and formation of $C-C$ and $C=C$ bonds $[25,31-34]$.

\subsection{Differential Scanning Calorimetry (DSC) and Thermogravinetric Analysis (TGA)}

Differential scanning calorimetry (DSC) and thermogravimetric analysis (TGA) were conducted to examine whether the thermostabilisation was effective in terms of eliminating thermoplasticity of the raw material. The DSC graphs of both untreated and thermostabilised lignin show an exothermal behaviour during heating from ambient temperature up to $300{ }^{\circ} \mathrm{C}$ (Figure 5a), which is more pronounced in the thermostabilised lignin compared to the untreated sample. A small but clear local minimum in the DSC curve of the untreated sample at a temperature of $230^{\circ} \mathrm{C}$ indicates softening. As this local minimum vanishes entirely after thermostabilisation, this procedure is expected to be efficient in terms of preventing thermal fusing of the lignin during carbonisation.

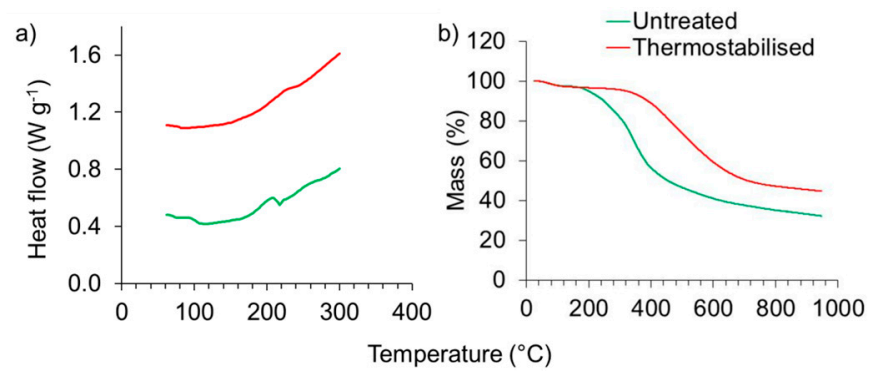

Figure 5. DSC (a) and TGA (b) curves of organosolv lignin particles prior to and after thermostabilisation. 
TGA showed the mass loss, thermal and oxidation stability and the decomposition temperature of the lignin powders during heat treatment under nitrogen atmosphere (Figure $5 b$ ). There was an insignificant initial mass loss due to moisture removal [27]. The start of mass loss of the untreated lignin was detected at $170{ }^{\circ} \mathrm{C}$. The thermogravimetry curve of the thermostabilised lignin shifted toward a higher temperature with the start of mass loss at $300{ }^{\circ} \mathrm{C}$, which indicates an increasing thermal stability and longer temperature resistivity, longer stability and a later decomposition. The overall loss pattern was determined with $67 \%$ for the untreated lignin sample and in contrast to this the mass loss of the thermostabilised lignin was observed with $58 \%$ which approximates a total mass loss of $82 \%$ compared to the starting mass. The stagnation of the drop of the thermogravimetry curve shows that the decomposition of lignin terminates due to charring [35]. The results of TGA are in line with what was shown with DSC, the thermostabilisation was successfully conducted.

It should be mentioned here that it is known that the stabilisation process of lignin and the properties of the carbonised products largely depend on the lignin source (e.g., hardwood or softwood) because of important differences in composition and molecular weight distribution [36].

\subsection{X-ray Powder Diffraction}

Structural alterations of organosolv lignin as a result of thermostabilisation and carbonisation were confirmed by X-ray diffractometry (Figure 6).

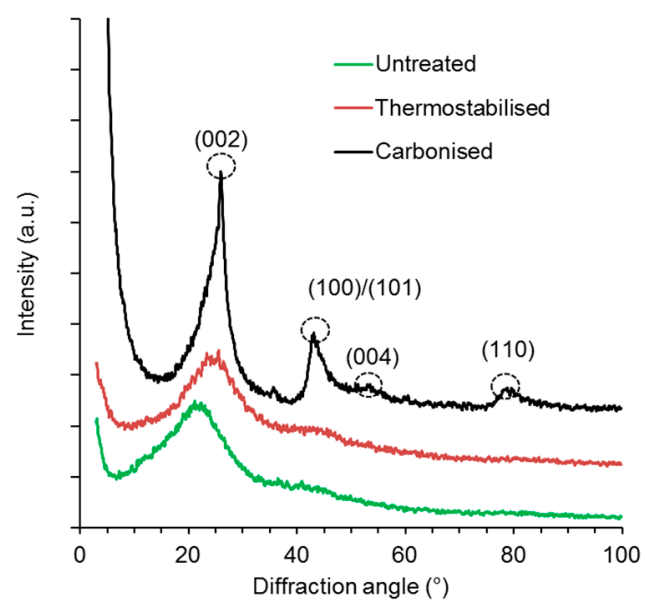

Figure 6. XRD patterns of organosolv lignin microparticles prior to and after thermostabilisation and carbonisation.

The XRD patterns of the untreated and the thermostabilised lignin powder are almost congruent and do not show well-defined peaks, which indicates a non-crystalline powder. After carbonisation, the XRD patterns show four peaks at diffraction angles of $26.7^{\circ}(002), 43.2^{\circ}(100) /(101), 54.7^{\circ}(004)$ and $78.1^{\circ}(110)$ confirming the occurrence of structural changes during carbonisation. Supramolecular rearrangement to partly graphitic structures is evident from sharpening of the (002) and (100)/(101) diffraction peaks and appearing of (004) and (110) peaks [37]. Graphite structures are formed during carbonisation by lignin dehydration, decarbonylation, decarboxylation as well as rearrangement and extension of the network of sp2 hybridised carbon formed by aromatic moieties inherent to lignin [24]. This takes place because the fundamental structure of the lignin is not affected for the most part, only side groups are cleaved and faded. Thus, graphene-like structures are built during carbonisation because of the dissociation of non-carbon atoms $[6,38]$.

\subsection{Small Angle X-ray Scattering}

Small angle $X$-ray scattering experiments revealed a very similar morphology for the lignin particles prior to and after oxidative thermo-stabilisation, as evident from the similar decay of the scattering curves with increasing $q$ values (Figure 7). Both curves can be fitted using an exponent 
close to four. The latter and the absence of any special feature suggest the material composed of poorly defined structures that feature very broad size distribution at the nano-scale. The existence of a slightly broader shoulder centered at about $q=0.5 \mathrm{~nm}^{-1}$ for the thermo-stabilised sample however is indicative for the development of some nano-porous structures during the oxidative activation step. In contrast, the broad peak of the scattering curve of the carbonised sample at a higher scattering vector $(0.6 \leqslant q \leqslant 4)$ unambiguously reveals the formation of a highly nano-porous material of distinct size.

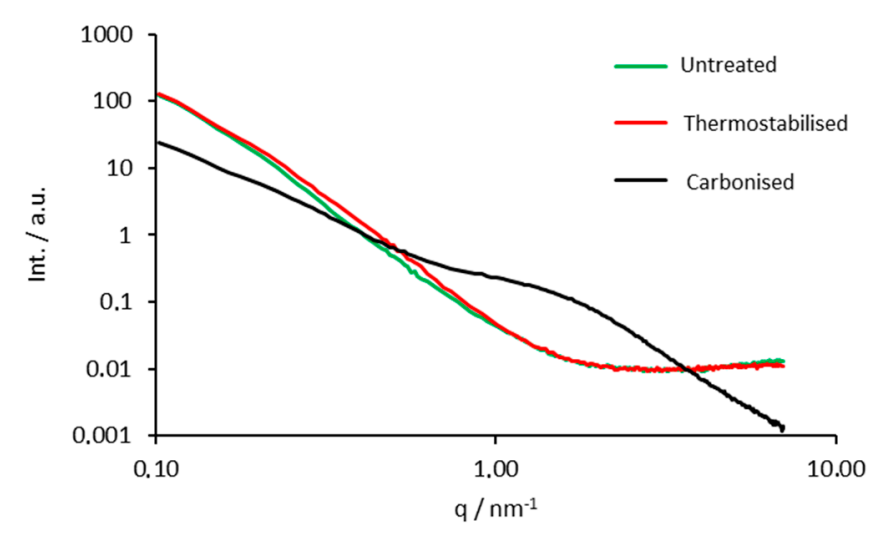

Figure 7. SAXS curves of the untreated, thermostabilised and carbonised organosolv lignin particles.

Application of the Guinier evaluation reveals a mean pore radius of $R=(1.06 \pm 0.04) \mathrm{nm}$ for the carbonised lignin powder, assuming spherical pores. Also the exponent in the Porod regime is less than four, indicating a higher surface roughness. The $P / Q$ ratio representing the total pore surface (open and closed pores) per volume increases slightly from 97 to $130 \mathrm{~m}^{2} \cdot \mathrm{cm}^{-3}$ during thermostabilisation but strongly from 130 to $770 \mathrm{~m}^{2} \cdot \mathrm{cm}^{-3}$ during carbonisation ( $c f$. Table 1 ).

Table 1. Pore radius of the untreated, thermostabilised and carbonised lignin samples. Errors of the respective fit and calculations, respectively, are given in brackets.

\begin{tabular}{cccc}
\hline Sample Name & $n$ & $P / Q\left(\mathbf{m}^{2} \cdot \mathbf{c m}^{-3}\right)$ & $R /(\mathbf{n m})$ \\
\hline untreated & $-3.85(5)$ & $97(20)$ & - \\
thermostabilised & $-3.87(2)$ & $130(30)$ & - \\
carbonised & $-3.45(2)$ & $770(50)$ & $1.06(4)$ \\
\hline
\end{tabular}

In conclusion, the conducted SAXS experiments confirmed that the parent lignin powder had no defined pore structure at the nanoscale. Thermostabilisation did not alter the nanostructure significantly, only a slight increase of specific surface and indication for a somewhat higher nanoporosity was found (higher scattering intensity at respective q values). After carbonisation the material shows a clear pore structure, corresponding to the appereance of a distinct shoulder in the scattering curve, attributed to a pore size of about $1 \mathrm{~nm}$ and an increase of the specific surface by a factor of six $\left(770 \mathrm{~m}^{-2} \cdot \mathrm{cm}^{-3}\right)$, compared to the thermostabilised sample. The decreased exponent of the power law in the Porod regime of the scattering curve can be related to a higher surface roughness of the material.

\subsection{Specific Electrical Resistivity}

The specific electrical resistivity of the carbonised lignin particles was determined to evaluate their potential application for imparting organic polymers electro-conductivity. It can be seen in Figure 8 that the specific resistivity of carbon particles obtained in this study is in the range of $0.079 \Omega \mathrm{m}$ under atmospheric pressure, and $0.001 \Omega \mathrm{m}$ at a pressure of $0.51 \mathrm{MPa}$ (Figure 8a). The resistivity 
diminishes with higher pressure. These findings are in good agreement with recent studies of electrical conductivity of carbon based particles derived from lignin [19,39-41]. It is known that heteroelements on the surface of carbonaceous materials can decrease total conductivity [39]. As mentioned, the carbon particles obtained in this study consisted of 96.66 at \% of carbon and 3.20 at \% of oxygen (cf. Figure 3). In comparison, carbon black particles obtained in a very similar way were reported to have an electrical resistivity of $0.004 \Omega \mathrm{m}$ under atmospheric pressure up to $0.025 \Omega \mathrm{m}$ at a pressure of $0.48 \mathrm{MPa}$, with a resistivity highly dependent on the extent of structural homogeneity of the prepared carbon blacks [19]. Increasing structural homogeneity generally translates into decreasing resistivity.
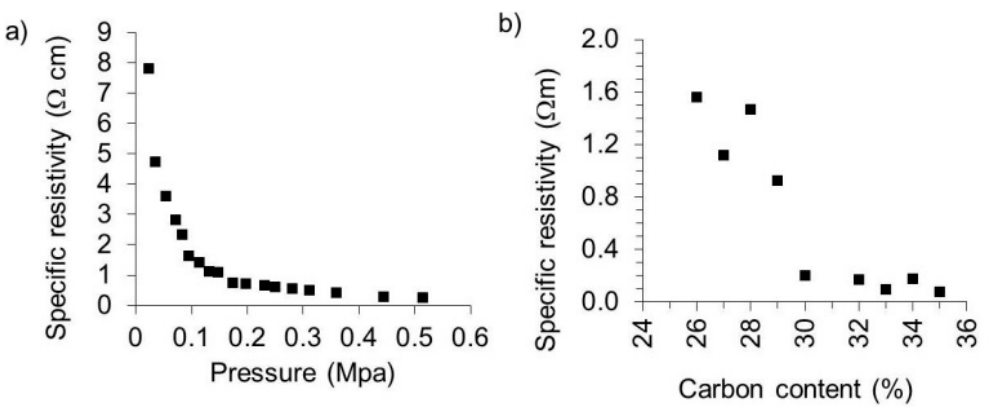

Figure 8. (a) Pressure dependence of specific resistivity for carbon particles made of organosolv lignin particles; (b) Effect of carbon microparticle content on specific resistivity of poly (lactic acid).

\subsection{Conducting Poly(Lactic Acid) (PLA) Carbon Composites}

Poly(lactic acid)/carbon composites were produced by incorporating different amounts of the lignin-derived carbon powders obtained in this study into diluted solutions of PLA in chloroform and subsequent evaporation of the organic solvent. PLA was chosen as matrix polymer because this polymer is easy to handle, biodegradable and thermoplastic. It has evoked a great interest and is one of the most interesting biopolymers. There is a wide range of applications for PLA, especially for medical and biological tasks as well as packaging [42]. The obtained composite materials were found to become electrically conductive above a carbon loading of $26 \%$ (Figure $8 \mathrm{~b}$ ). Beyond this percolation threshold, conducting pathways are increasingly established within the polymer as reflected by resistivity that dropped from $1.6 \Omega \mathrm{m}$ ( $26 \%$ loading) to $0.21 \Omega \mathrm{m}$ when $35 \mathrm{wt} \%$ of carbon particles were incorporated [43]. However, compared to other studies, carbon loading to achieve electro-conductivity is still very high. Carbon black for example has been reported to impart high electrical conductivity to high-density polyethylene (HDPE) already at loading of $3 \mathrm{wt} \%$ [44]. In a recent study it was demonstrated that graphitised carbon black as filler in Poly(L-lactide) (PLLA) caused a decrease of resistivity from $1.6 \times 10^{3} \Omega \mathrm{m}$ for unfilled PLLA to values lower than $1 \Omega \mathrm{m}$ with a concentration of carbon black of $10 \mathrm{wt} \%$ [45]. It is assumed that insufficiently homogeneous dispersion of particles (Figure 9) that were not surface-modified to improve compatibility with the PLA matrix may be one of the reasons for the high loadings required to reach the percolation threshold. The simple folding and hot-pressing method applied in our study clearly improved carbon dispersion in the PLA films cast from solution. However, further improvements could be achieved by proper melt-compounding by means of e.g. extrusion. It is known that the tunneling distance of electrons in carbon black-polymer systems depends on many factors and that there is no linear collective effect [9]. Liu et al. found that electrical resistance can be described by the tunneling conduction and percolation theory but that the electrical conductivity is dependent of the radius position [46]. In contrast, the tunneling distance of electrons in carbon nanotube polymer matrixes was found to be $1.8 \mathrm{~nm}$ [47]. The network of the carbon particles has to have smaller distance than this tunneling distance, otherwise there will be no electrical conductivity. The agglomeration of lignin-derived carbon powder in the PLA may be a reason for the need for high loadings of carbon powder. To reach a lower percolation threshold, the surface area can be enhanced, the structure should be higher and the volatile content should be the lowest possible [48]. 

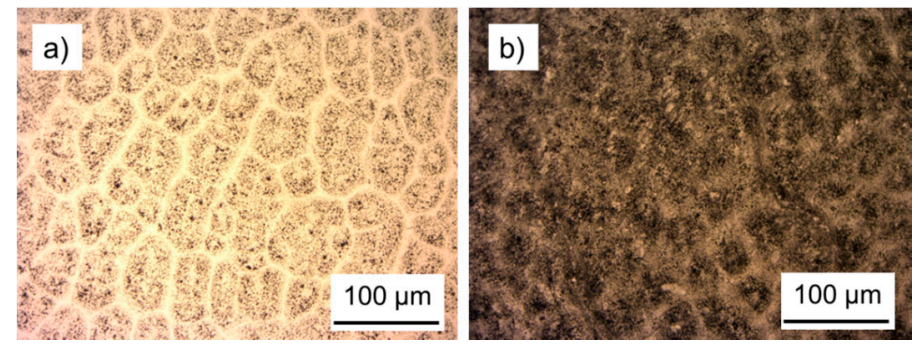

Figure 9. Optical micrographs of PLA films with $10 \%$ filler content showing (a) poor dispersion of carbon particles after casting from solution and (b) improved dispersion after repeated hot-pressing.

\subsection{Mechanical Properties of Poly(Lactic Acid) (PLA) Carbon Composites}

Tensile testing of PLA specimen loaded with different amounts of carbon particles revealed that both tensile strength and failure strain decreased with the addition of carbon particles to a certain extent (Figure 10). The tensile strength dropped from $25 \mathrm{MPa}$ for PLA without lignin particles to $13 \mathrm{MPa}$ for PLA filled with 5\% carbonaceous lignin powder. For PLA filled with 5\%-35\% of the carbonaceous powder, the tensile strength is almost steady. Failure strain also decreased. Without carbon filling it was about $1.5 \%$. After adding only $5 \%$ lignin derived carbon, the failure strain fell to $0.8 \%$. Between $5 \%$ and $35 \%$ carbon loading, the failure strain was almost steady. Other studies found that the tensile strength increases with low loadings and decreases with high loadings. It was also found that the influence of carbon black particles differs a lot depending on the polymer matrix material [48]. In this case, agglomerates of the carbon particles can lead to imperfections in mechanical testing. The largest carbon particles, which were measured with $60 \mu \mathrm{m}$, can also lead to breakages.

In contrast to the decrease of tensile strength and failure strain, the Young modulus E seems to increase slightly at higher loadings. Overall, the effects of carbon filler on the mechanical performance of PLA are in agreement with other studies [49,50]. As outlined in a review on mechanics of particulate-filled polymers [51] an increase in composite stiffness in parallel with a reduction in tensile strength and extensibility is principally observed upon addition of particulate fillers. However, as shown in Figure 10, the PLA-carbon composites produced in the present study do not show a distinctly proportional relationship between filler content and change in mechanics, which one would expect. As with electrical conductivity of the PLA composites, it is proposed that improved filler dispersion by e.g. extrusion may lead to clearer relationships through reduced variability.

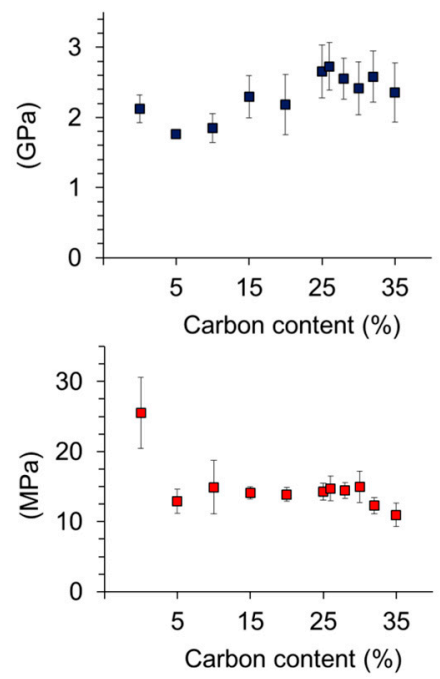

$$
\begin{aligned}
& \text {-Modulus of elasticity } \\
& \text { - Tensile strength } \\
& \text { - Failure strain }
\end{aligned}
$$

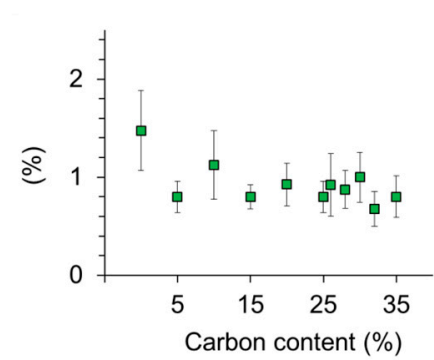

Figure 10. Relationship between mechanical properties and lignin-based carbon microparticle loading of poly(lactic acid) composites. 


\section{Conclusions}

The results of this study are encouraging with respect to the production of conducting polymers using carbon particles derived from a specific technical lignin that is commercially available and produced by organosolv pulping of grass lignin. Even though reasonably low electrical resistivity was measured for the carbonised lignin particles, comparatively high carbon loadings were required to impart conductivity to poly(lactic acid), indicating that further research on lignin-based carbon particles is necessary.

Acknowledgments: Financial support by the Austrian Research Promotion Agency FFG, project 846543 is gratefully acknowledged.

Author Contributions: Janea Köhnke performed the majority of experiments and wrote the majority of the paper. Christian Fürst and Christoph Unterweger carried-out carbonisation. Jozef Keckes, Helga C. Lichtenegger, and Harald Rennhofer performed X-ray characterisation. Gerhard Emsenhuber performed electrical conductivity measurements. Arunjunai raj Mahendran carried-out thermal analysis. Falk Liebner and Wolfgang Gindl-Altmutter conceived the experiments, contributed significant parts to the paper, and supervised writing.

Conflicts of Interest: The authors declare no conflict of interest. The founding sponsors had no role in the design of the study; in the collection, analyses, or interpretation of data; in the writing of the manuscript, and in the decision to publish the results.

\section{References}

1. El Mansouri, N.-E.; Salvadó, J. Analytical methods for determining functional groups in various technical lignins. Ind. Crop. Prod. 2007, 26, 116-124. [CrossRef]

2. Belgacem, M.N.; Gandini, A. Monomers, Polymers and Composites from Renewable Resources; Elsevier Ltd.: London, UK, 2008.

3. Lin, S.Y.; Dence, C.W. Methods in Lignin Chemistry; Springer: Berlin, Germany, 1992.

4. Lora, J.H.; Glasser, W.G. Recent industrial applications of lignin: A sustainable alternative to nonrenewable materials. J. Polym. Environ. 2002, 10, 39-48. [CrossRef]

5. Baker, D.A.; Rials, T.G. Recent advances in low-cost carbon fiber manufacture from lignin. J. Appl. Polym. Sci. 2013, 130, 713-728. [CrossRef]

6. Chand, S. Carbon fibers for composites. J. Mater. Sci. 2000, 35, 1303-1313. [CrossRef]

7. Kadla, J.F.; Kubo, S.; Venditti, R.A.; Gilbert, R.D.; Compere, A.L.; Griffith, W. Lignin-based carbon fibers for composite fiber applications. Carbon 2002, 40, 2913-2920. [CrossRef]

8. Ruiz-Rosas, R.; Bedia, J.; Lallave, M.; Loscertales, I.G.; Barrero, A.; Rodríguez-Mirasol, J.; Cordero, T. The production of submicron diameter carbon fibers by the electrospinning of lignin. Carbon 2010, 48, 696-705. [CrossRef]

9. Balberg, I. A comprehensive picture of the electrical phenomena in carbon black-polymer composites. Carbon 2002, 40, 139-143. [CrossRef]

10. Geim, A.K.; Novoselov, K.S. The rise of graphene. Nat. Mater. 2007, 6, 183-191. [CrossRef] [PubMed]

11. Zhang, H.; Wang, C.; Zhang, Y. Preparation and properties of styrene-butadiene rubber nanocomposites blended with carbon black-graphene hybrid filler. J. Appl. Polym. Sci. 2015, 132. [CrossRef]

12. Ma, L.-F.; Bao, R.-Y.; Huang, S.-L.; Liu, Z.-Y.; Yang, W.; Xie, B.-H.; Yang, M.-B. Electrical properties and morphology of carbon black filled PP/EPDM blends: Effect of selective distribution of fillers induced by dynamic vulcanization. J. Mater. Sci. 2013, 48, 4942-4951. [CrossRef]

13. Feller, J.-F.; Petitjean, É. Conductive polymer composites(cpc): Influence of processing conditions, shear rate and temperature on electrical properties of poly(butylene terephthalate)/poly(amide12-btetramethyleneglycol)- carbon black blends. Macromol. Symp. 2003, 203, 309-316. [CrossRef]

14. Schulze, P.; Seidel-Morgenstern, A.; Lorenz, H.; Leschinsky, M.; Unkelbach, G. Advanced process for precipitation of lignin from ethanol organosolv spent liquors. Bioresour. Technol. 2016, 199, 128-134. [CrossRef] [PubMed]

15. Mansouri, N.-E.E.; Salvadó, J. Structural characterization of technical lignins for the production of adhesives: Application to lignosulfonate, kraft, soda-anthraquinone, organosolv and ethanol process lignins. Ind. Crops Prod. 2006, 24, 8-16. [CrossRef] 
16. Zhang, K.; Pei, Z.; Wang, D. Organic solvent pretreatment of lignocellulosic biomass for biofuels and biochemicals: A review. Bioresour. Technol. 2016, 199, 21-33. [CrossRef] [PubMed]

17. Tejado, A.; Pena, C.; Labidi, J.; Echeverria, J.M.; Mondragon, I. Physico-chemical characterization of lignins from different sources for use in phenol-formaldehyde resin synthesis. Bioresour. Technol. 2007, 98, 1655-1663. [CrossRef] [PubMed]

18. El Hage, R.; Brosse, N.; Chrusciel, L.; Sanchez, C.; Sannigrahi, P.; Ragauskas, A. Characterization of milled wood lignin and ethanol organosolv lignin from miscanthus. Polym. Degrad. Stab. 2009, 94, 1632-1638. [CrossRef]

19. Sánchez-González, J.; Macías-García, A.; Alexandre-Franco, M.F.; Gómez-Serrano, V. Electrical conductivity of carbon blacks under compression. Carbon 2005, 43, 741-747. [CrossRef]

20. Gindl-Altmutter, W.; Fürst, C.; Mahendran, A.R.; Obersriebnig, M.; Emsenhuber, G.; Kluge, M.; Veigel, S.; Keckes, J.; Liebner, F. Electrically conductive kraft lignin-based carbon filler for polymers. Carbon 2015, 89, 161-168. [CrossRef]

21. Dwiyanti, M.S.; Stewart, J.R.; Yamada, T. Forages for feedstocks of biorefineries in temperate environments: Review of lignin research in bioenergy crops and some insight into miscanthus studies. Crop Pasture Sci. 2014, 65, 1199-1206. [CrossRef]

22. Kuo, D.T.F.; Vander Sande, J.B.; Gschwend, P.M. Characterization of black carbon in geosorbents at the nanometer scale by stem-edx elemental mapping. Org. Geochem. 2013, 56, 81-93. [CrossRef]

23. Norberg, I.; Nordström, Y.; Drougge, R.; Gellerstedt, G.; Sjöholm, E. A new method for stabilizing softwood kraft lignin fibers for carbon fiber production. J. Appl. Polym. Sci. 2013, 128, 3824-3830. [CrossRef]

24. Sharma, R.K.; Wooten, J.B.; Baliga, V.L.; Lin, X.; Geoffrey Chan, W.; Hajaligol, M.R. Characterization of chars from pyrolysis of lignin. Fuel 2004, 83, 1469-1482. [CrossRef]

25. Braun, J.L.; Holtman, K.M.; Kadla, J.F. Lignin-based carbon fibers: Oxidative thermostabilization of kraft lignin. Carbon 2005, 43, 385-394. [CrossRef]

26. Kubo, S.; Kadla, J.F. Hydrogen bonding in lignin: A fourier transform infrared model compound study. Biomacromolecules 2005, 6, 2815-2821. [CrossRef] [PubMed]

27. Yang, H.; Yan, R.; Chen, H.; Lee, D.H.; Zheng, C. Characteristics of hemicellulose, cellulose and lignin pyrolysis. Fuel 2007, 86, 1781-1788. [CrossRef]

28. Britt, P.F.; Buchanan, A.C., III; Malcolm, E.A. Thermolysis of phenethyl phenyl ether: A model for ether linkages in lignin and low rank coal. J. Org. Chem. 1995, 60, 6523-6536. [CrossRef]

29. Nimz, H. Über eine neuartige umlagerung in der ligninchemie. Angew. Chem. 1966, 78, 821-822. [CrossRef]

30. Schmidt, J.A.; Rye, C.S.; Gurnagul, N. Lignin inhibits autoxidative degradation of cellulose. Polym. Degrad. Stab. 1995, 49, 291-297. [CrossRef]

31. Drbohlav, J.; Stevenson, W.T.K. The oxidative stabilization and carbonization of a synthetic mesophase pitch, part I: The oxidative stabilization process. Carbon 1995, 33, 693-711. [CrossRef]

32. Drbohlav, J.; Stevenson, W.T.K. The oxidative stabilization and carbonization of a synthetic mesophase pitch, part II: The carbonization process. Carbon 1995, 33, 713-731. [CrossRef]

33. Matsumoto, T.; Mochida, I. A structural study on oxidative stabilization of mesophase pitch fibers derived from coaltar. Carbon 1992, 30, 1041-1046. [CrossRef]

34. Sahoo, S.; Seydibeyoğlu, M.Ö.; Mohanty, A.K.; Misra, M. Characterization of industrial lignins for their utilization in future value added applications. Biomass Bioenergy 2011, 35, 4230-4237. [CrossRef]

35. Wang, Y.; Xie, W. Synthesis of cationic starch with a high degree of substitution in an ionic liquid. Carbohydr. Polym. 2010, 80, 1172-1177. [CrossRef]

36. Saito, T.; Perkins, J.H.; Vautard, F.; Meyer, H.M.; Messman, J.M.; Tolnai, B.; Naskar, A.K. Methanol fractionation of softwood kraft lignin: Impact on the lignin properties. Chemsuschem 2014, 7, $221-228$. [CrossRef] [PubMed]

37. Li, Z.Q.; Lu, C.J.; Xia, Z.P.; Zhou, Y.; Luo, Z. X-ray diffraction patterns of graphite and turbostratic carbon. Carbon 2007, 45, 1686-1695. [CrossRef]

38. Foston, M.; Nunnery, G.A.; Meng, X.; Sun, Q.; Baker, F.S.; Ragauskas, A. NMR a critical tool to study the production of carbon fiber from lignin. Carbon 2013, 52, 65-73. [CrossRef]

39. Pantea, D.; Darmstadt, H.; Kaliaguine, S.; Sümmchen, L.; Roy, C. Electrical conductivity of thermal carbon blacks. Carbon 2001, 39, 1147-1158. [CrossRef] 
40. Celzard, A.; Marêché, J.F.; Payot, F.; Furdin, G. Electrical conductivity of carbonaceous powders. Carbon 2002, 40, 2801-2815. [CrossRef]

41. Chung, D.D.L. Electrical applications of carbon materials. J. Mater. Sci. 2004, 39, 2645-2661. [CrossRef]

42. Nampoothiri, K.M.; Nair, N.R.; John, R.P. An overview of the recent developments in polylactide (PLA) research. Bioresour. Technol. 2010, 101, 8493-8501. [CrossRef] [PubMed]

43. Li, F.; Qi, L.; Yang, J.; Xu, M.; Luo, X.; Ma, D. Polyurethane/conducting carbon black composites: Structure, electric conductivity, strain recovery behavior, and their relationships. J. Appl. Polym. Sci. 2000, 75, 68-77. [CrossRef]

44. Ren, D.; Zheng, S.; Wu, F.; Yang, W.; Liu, Z.; Yang, M. Formation and evolution of the carbon black network in polyethylene/carbon black composites: Rheology and conductivity properties. J. Appl. Polym. Sci. 2014, 131. [CrossRef]

45. Tsuji, H.; Kawashima, Y.; Takikawa, H.; Tanaka, S. Poly(L-lactide)/nano-structured carbon composites: Conductivity, thermal properties, crystallization, and biodegradation. Polymer 2007, 48, 4213-4225. [CrossRef]

46. Liu, X.; Kruckel, J.; Schubert, D.W. Building and testing a simple setup to investigate the electrical properties of polymer/carbon black composites. Compos. Struct. 2015, 129, 55-59. [CrossRef]

47. Li, C.Y.; Thostenson, E.T.; Chou, T.W. Dominant role of tunneling resistance in the electrical conductivity of carbon nanotube-based composites. Appl. Phys. Lett. 2007, 91. [CrossRef]

48. Huang, J.-C. Carbon black filled conducting polymers and polymer blends. Adv. Polym. Technol. 2002, 21, 299-313. [CrossRef]

49. Nerantzaki, M.; Papageorgiou, G.Z.; Bikiaris, D.N. Effect of nanofiller's type on the thermal properties and enzymatic degradation of poly( $\varepsilon$-caprolactone). Polym. Degrad. Stab. 2014, 108, 257-268. [CrossRef]

50. Kim, K.H.; Jo, W.H. A strategy for enhancement of mechanical and electrical properties of polycarbonate/multi-walled carbon nanotube composites. Carbon 2009, 47, 1126-1134. [CrossRef]

51. Fu, S.-Y.; Feng, X.-Q.; Lauke, B.; Mai, Y.-W. Effects of particle size, particle/matrix interface adhesion and particle loading on mechanical properties of particulate-polymer composites. Compos. B Eng. 2008, 39, 933-961.

(C) 2016 by the authors; licensee MDPI, Basel, Switzerland. This article is an open access article distributed under the terms and conditions of the Creative Commons Attribution (CC-BY) license (http://creativecommons.org/licenses/by/4.0/). 